\title{
Parameterized finite element analysis of a superplastic forming process, using Ansys ${ }^{\circledR}$
}

\author{
Gavril Grebenişan ${ }^{1 *}$, Sanda Bogdan ${ }^{2}$ \\ ${ }^{1}$ University of Oradea, e-mail: grebe@uoradea.ro \\ ${ }^{2}$ University of Oradea, e-mail: sandaromocea@yahoo.com
}

\begin{abstract}
A theoretical and experimental analysis was carried out, after superplastic forming, of Al-Ti-V-based alloy sheets, of hemispherical parts, as the start point of research. Based on the measurements i.e. the quantitative and qualitative determinations of the manufactured parts, work reports have been prepared to contain the magnitude of variations in the thickness of the parts, in cross-section, as well as references to the surface quality and the local thinning of the walls of the part. The experimental study was followed by a parameterized finite elements analysis of the process, using Ansys ${ }^{\circledR}$, Explicit Dynamics Module, This being for examining the next step of our study, comparing the experimental results with the theoretical analysis, based on two input parameters: and discussing the results, and very necessary, the correlation between input and output parameters, mainly the influence magnitude rate of input parameters on output parameters.
\end{abstract}

\section{Introduction}

The parameterized analysis has as its main objective the discovery and accentuation of the role of each input parameter on the evolution of the process, mainly on the output parameters chosen by the operator. It is known that superplastic forming is a process whose duration is superior to similar plastic deformation processes, primarily due to the extremely low strain rate. This major disadvantage in the economy of the process and the calculation of economic efficiency is countered by the broad applicability of this process in areas of particular interest: aeronautics, automobiles, medicine, and robotics.

The superplasticity is defined in the scientific literature as a more metallurgical phenomenon and is manifested in some materials, mainly alloys based on $\mathrm{Al}, \mathrm{Ti}, \mathrm{V}, \mathrm{Zn}$, $\mathrm{Cu}$, but also on some low carbon steels. These alloys or metals, which have superplastic characteristics, exhibit a long and uniform deformation at extremely low deformation rates and relatively high temperatures ( $>$ $0.5 \mathrm{~T}_{\text {melt }}$, and the grain structure is characterized by grain sizes of about 10 micrometers. The term "superplasticity" was introduced in 1945 by A.A. Bochvar and Z.A. Sviderskaia [1] when analyzing the behavior of the $\mathrm{Zn}+22 \% \mathrm{Al}$ eutectic alloy, having an ultrafine structure. Since 1960, the phenomenon has been researched for promising practical applications, which has determined that the main conditions for the development of superplastic behavior are elucidated and then created in metallurgical research labs. In particular, the realization of the granular microstructure, the methods of grinding the rough structure, and the reduction of grain sizes up to $10 \mu \mathrm{m}$, have been achieved successfully. Another parameter of superplastic deformation, namely strain rate, which was estimated to be effective, in the range $\left(10^{-5}\right.$ to $\left.10^{-1}\left[\mathrm{~s}^{-1}\right]\right)$, at relatively high temperature $\left(>0.5 \mathrm{~T}_{\text {melt }}\right.$, where $\mathrm{T}_{\text {melt }}$ is the melting temperature of the alloy expressed in $[\mathrm{K}]$ ) at low values of deformation pressure., made this technology to be received with caution by engineering technology science. But the advantages that superplastic deformed parts exhibit, the dimensional fidelity, the accuracy of multiple profiles, and the dimensional stability at temperature variations in the operating environment, such as those in the aerospace industry, have recommended this process as an extremely efficient and suitable one for cutting edge technology. Using alloy $\mathrm{Zn}$ $+22 \% \mathrm{Al}$ alloy, W.A. Backofen, I.R. Turner, and D.H. Avery [2] conducted tests and researches on the behavior of this material in simple traction and extrusion respectively, then processing, from this material, parts with a relatively complex configuration as a geometric profile. The $\mathrm{Zn}+22 \% \mathrm{Al}$ superplastic alloy plate had a thickness of $\mathrm{s}=0.76(\mathrm{~mm})$, the diameter of the die was $100(\mathrm{~mm})$, and the working air pressure in the die was 0.1 to $0.2(\mathrm{MPa})$.

The special structure, i.e. the ultrafine structure, as the most significant constraint on the superplastic behavior

\footnotetext{
"Corresponding author: grebe@uoradea.ro
} 
of the material, is the size of the ultra-fine granules, which must be less than 10 micrometers. From the metallurgical phenomena that characterize superplastic behavior, the balance between maintaining the ultra-fine grain structure, coagulation development, and growth (at deformation temperature) is one of the main objectives of the study of superplastic behavior in the world. Methods of refining the structure, which can be summarized in the following consecutive types: phase separation, the phase transformation or mechanical processing accompanied by recrystallization are used for the majority of superplastic materials.

It should be emphasized, however, that the realization of ultra-fine structures is not a sufficient condition to guarantee the behavior of a superplastic material but must provide methods and conditions for maintaining the fine grain size. Grain growth is highlighted in superplastic areas deformed, and non-deformed areas are less (experimental observations).

The superplastic behavior of materials is characterized by law established by W.A. Backofen, I.R. Turner, and D.H. Avery [2], known as an extended power-law model:

$\overline{\boldsymbol{\sigma}}=\mathbf{K} \cdot \boldsymbol{\varepsilon}^{\mathbf{n}} \cdot \dot{\bar{\varepsilon}}^{\mathbf{m}}$

where $\bar{\sigma} \mathrm{s}$ is the equivalent flow stress, $K$ is the strength coefficient, $\varepsilon$ is the equivalent strain, $n$ is the workhardening index, $\dot{\bar{\varepsilon}}$ is the equivalent strain rate, and $m$ is the strain rate sensitivity index, the mathematical expression of which is given by $\mathbf{m}=\ln ($ stress $) / \ln ($ strain rate $)$ the gradient of the

logarithmic curve. Other authors, N. Chandra [3], proposed a more comprehensive expression of the uniaxial flow stress. This is seen to be a highly dependent of inelastic strain-rate $\dot{\bar{\varepsilon}}$ and a weak function of strain $\varepsilon$ and grain size $d$ :

$\boldsymbol{\sigma}=\mathbf{f}(\boldsymbol{\varepsilon}, \dot{\varepsilon}, \mathbf{d})$

which expressed in the logarithmic form, become:

$\ln \sigma=\mathbf{F}(\ln \varepsilon, \ln \dot{\varepsilon}, \ln d)$

That may be written in the manner expanded as Taylor series, at a given equilibrium state, with neglecting the higher order terms:

$\sigma=K_{1} \cdot \varepsilon^{n} \cdot \dot{\varepsilon}^{m} \cdot d^{p}$

Where we denoted $K_{1}, m, n, p$, are the material's coefficients, having the mathematical forms: $n=$ $\frac{\partial(\ln \sigma)}{\partial(\ln \varepsilon)} ; m=\frac{\partial(\ln \sigma)}{\partial(\ln \dot{\varepsilon})} ; p=\frac{\partial(\ln \sigma)}{\partial(\ln d)}, \quad$ with the following significant expressions: $m$ is the strain rate sensitivity, $n$ is the strain hardening exponent, and $p$ is the grain growth exponent.

For the study that we are going to accomplish, we should, theoretically at least, to find some evaluations regarding the influence of some of the geometric parameters, material parameters, respectively technological parameters, on the output parameters, in a design study. These assessments, in the alternative, could lead to a project optimization analysis using either single objective or multi-objective methods, depending on project constraints. Thus, using the studies presented by P, F. Dunne and N. Petrinic [4], a cylindrical specimen with the initial dimensions $L$ (length) and $A$ (undeformed area) upon which a force acts, will be characterized, after deformation, by the following parameters: $\mathrm{A}+\mathrm{dA}, \mathrm{L}+\mathrm{dL}, \sigma+\mathrm{d} \sigma, \dot{\varepsilon}+\mathrm{d} \dot{\varepsilon}$, respectively. By imposing the incompressibility condition, so the volume remains constant, by neglecting the infinitesimal small terms, it is obtained:

$\mathbf{A L}=(\mathbf{A}+\mathbf{d A})(\mathbf{L}+\mathbf{d L}) \approx \mathbf{A L}+\mathbf{L d A}+\mathbf{A d L}$

one obtain

$\frac{\mathrm{dA}}{\mathrm{dt}}=-\dot{\boldsymbol{\varepsilon}} \mathrm{A}$

which, become (applied for deformed zone):

$\frac{\mathbf{d}(\mathbf{A}+\mathbf{d A})}{\mathbf{d t}}=-(\dot{\boldsymbol{\varepsilon}}+\mathbf{d} \dot{\boldsymbol{\varepsilon}})(\mathbf{A}+\mathbf{d A})$

So:

$\frac{d}{d t}(d A) \approx-(\mathbf{A d} \dot{\varepsilon}+\dot{\varepsilon} d A)=-\dot{\varepsilon} d A\left(\frac{A}{d A} \frac{d \dot{\varepsilon}}{\dot{\varepsilon}}+1\right)$

As the force is constant, we obtain:

$\boldsymbol{\sigma} \mathbf{A}=(\boldsymbol{\sigma}+\mathbf{d} \boldsymbol{\sigma})(\mathbf{A}+\mathbf{d A})$, or $\frac{\mathbf{d} \boldsymbol{\sigma}}{\boldsymbol{\sigma}}=-\frac{\mathbf{d A}}{\mathbf{A}}$

Applying the constitutive equation, expressed in effective values(we neglect, for the seek of comprehensibility and mathematical simplification): $\sigma=K \dot{\varepsilon}^{m}$, one obtain:

$\boldsymbol{\sigma}+\mathbf{d} \boldsymbol{\sigma}=\mathbf{K}(\dot{\varepsilon}+\mathbf{d} \dot{\varepsilon})^{\mathbf{m}}=\mathbf{K} \dot{\varepsilon}^{\mathbf{m}}\left(1+\frac{\mathbf{d} \dot{\varepsilon}}{\dot{\varepsilon}}\right)^{\mathbf{m}}=$

$\mathbf{K} \dot{\varepsilon}^{\mathbf{m}}\left[\mathbf{1}+\mathbf{m} \frac{\mathbf{d} \dot{\varepsilon}}{\dot{\varepsilon}}+\cdots\right]$

This relationship may be written as:

$\frac{\mathrm{d} \sigma}{\sigma} \approx \mathbf{m} \frac{\mathrm{d} \dot{\varepsilon}}{\dot{\varepsilon}}$, or $\frac{\mathrm{A}}{\mathrm{dA}} \frac{\mathrm{d} \dot{\varepsilon}}{\dot{\varepsilon}}=-\frac{1}{\mathrm{~m}}$

so that

$\frac{\mathrm{d}}{\mathrm{dt}}(\mathrm{dA}) \approx-\mathrm{dA} \dot{\varepsilon}\left(1-\frac{1}{\mathrm{~m}}\right)$

The previous relationship shows that the magnitude of deformation $\frac{\mathbf{d}}{\mathbf{d t}}(\mathbf{d A})$, depends on value of $\left(\mathbf{1}-\frac{\mathbf{1}}{\mathbf{m}}\right)$ term. Thus, it can be concluded that the strain rate sensitivity, $m$, increases, and takes 1 as value, while local necking, $\frac{d}{d t}(\mathbf{d A})$ decreases to zero. Hence, the significance of

\footnotetext{
*Corresponding author: grebe@,uoradea.ro
} 
strain sensitivity in the superplastic forming process resides: that is, the high value for there is no local gouging, which allows for a pronounced stretching. This is the essence of superplastic deformation: the ability of materials to exhibit very broad, uniform deformations without the appearance of local rusting. This is the explanation for which we chose Sample Diameter(this determine, or not(this will be revealed, after parameterized analysis results will be obtained) the magnitude of necking, as the first of the input parameters, with the objective of studying the influence of this parameter on stress deformation, strain deformation and total deformation(the output parameters).

\section{Experiments and parameterized analysis}

In order to setup the parameterized analysis a second input parameter was chosen: Sample_Thickness. We'll show, next steps, why we chosen this second geometrical parameter as an input parameter, to study the influence of output parameters, above named: stress deformation, strain deformation, and total deformation. Our demonstration is based on applying the membrane theory, G. Giuliano [5], in order to reveal the stress state in a thin sheet loaded by pressure $P$, with $s$ as thickness, $R_{\theta}$ and $R_{\varphi}$ are the curvature radii ( $R_{\theta}-$ meridian radius; $R_{\varphi}-$

circumpherential radii), fig. 1:
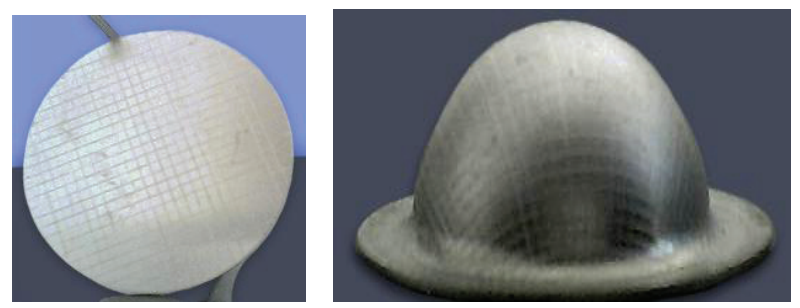

Fig. 1. The meshed sample(before the forming)-left; The meshed part, superplastic formed-right, G. Grebenişan and S. Mureşan [6]

Follow the assumptions, the state of equilibrium is described as:

$2 \sigma_{\varphi} \sin \left(\frac{d \varphi}{2}\right) s R_{\theta} d \theta+2 \sigma_{\theta} \sin \left(\frac{d \theta}{2}\right) s R_{\varphi} d \varphi=$ $\operatorname{pR}_{\varphi} \mathrm{d} \varphi \mathrm{R}_{\theta} \mathrm{d} \theta$,

moreover, assuming the forced approximation, $\sin \left(\frac{\mathrm{d} \varphi}{2}\right) \cong \frac{\mathrm{d} \varphi}{2}$, the previous equation may be rewritten as:

$\frac{\sigma_{\varphi}}{R_{\varphi}}+\frac{\sigma_{\theta}}{R_{\theta}}=\frac{p}{s}$

Using the evidence $\sigma_{\theta} \sin (\varphi) \cdot 2 \pi r s=p \pi r^{2}$, and $\mathbf{r}=$ $\mathbf{R}_{\boldsymbol{\varphi}} \sin (\boldsymbol{\varphi})$, than, the tangential stress, and the circumferential stress are estimated, respectively, with relationships:
$\sigma_{\theta}=\frac{\mathrm{pR}_{\varphi}}{2 \mathrm{~s}}$

$\sigma_{\varphi}=\frac{\mathbf{p R}_{\varphi}}{2 \mathrm{~s}}\left(2-\frac{\mathrm{R}_{\varphi}}{\mathrm{R}_{\theta}}\right)$

One may apply the von Mises criterion, for calculating the equivalent stress, for plain stress condition(assuming that the thickness stress $\sigma_{t}=0$ ):

$\bar{\sigma}=\sqrt{\sigma_{\theta}^{2}+\sigma_{\varphi}^{2}-\sigma_{\theta} \sigma_{\varphi}}=\frac{p R_{\varphi}}{2 s} \sqrt{\left(\frac{R_{\varphi}}{R_{\theta}}\right)^{2}-3 \frac{R_{\varphi}}{R_{\theta}}+3}$

Considering that the elastic strain is negligible, a relationship between stresses and strains magnitude, in the plastic domain, using the Levy-Mises flow rule to obtain the expressions for tangential $\left(\dot{\varepsilon}_{\boldsymbol{\theta}}\right)$, $\operatorname{circumferential}\left(\dot{\boldsymbol{\varepsilon}}_{\boldsymbol{\varphi}}\right)$ and thickness $\left(\dot{\boldsymbol{\varepsilon}}_{\mathrm{t}}\right)$ strain rate are as follows:

$\dot{\varepsilon}_{\theta}=\frac{\dot{\bar{\varepsilon}}}{\bar{\sigma}}\left[\sigma_{\theta}-\frac{1}{2}\left(\sigma_{\varphi}+\sigma_{t}\right)\right]$

$\dot{\varepsilon}_{\varphi}=\frac{\dot{\bar{\varepsilon}}}{\bar{\sigma}}\left[\sigma_{\varphi}-\frac{1}{2}\left(\sigma_{\theta}+\sigma_{t}\right)\right]$

$\dot{\varepsilon}_{\mathrm{t}}=\frac{\dot{\bar{\varepsilon}}}{\bar{\sigma}}\left[\sigma_{\mathrm{t}}-\frac{1}{2}\left(\sigma_{\varphi}+\sigma_{\theta}\right)\right]$

Considering the incompressibility law, so the volume variation is null $\left(\varepsilon_{\theta}+\varepsilon_{\varphi}+\varepsilon_{\mathrm{t}}=\right.$ const, $\dot{\varepsilon}_{\theta}+\dot{\varepsilon}_{\varphi}+\dot{\varepsilon}_{\mathrm{t}}=$ $\mathbf{0})$, the equivalent strain rate, calculated based on von Mises criterion is:

$\dot{\bar{\varepsilon}}=\frac{2}{\sqrt{3}} \sqrt{\dot{\varepsilon}_{\theta}^{2}+\dot{\varepsilon}_{\varphi}^{2}+\dot{\varepsilon}_{\theta} \dot{\varepsilon}_{\varphi}}$

The analyzed part is a hemisphere, and, by definition, $R_{\theta}=R_{\varphi}=R$, so one may write:

$\sigma_{\theta}=\sigma_{\varphi}=\frac{p R}{2 s}$

and Levy- Mises equations are:

$\dot{\bar{\varepsilon}}=-\dot{\varepsilon}_{\mathrm{t}}=2 \dot{\varepsilon}_{\theta}=2 \dot{\varepsilon}_{\varphi}$

We may use an empirical relationship for estimate the stresses:

$\sigma_{\theta}=\frac{p R}{2 s}$

$\sigma_{\varphi}=\frac{\sigma_{\theta}}{2}$

$\bar{\sigma}=\sqrt{3} \cdot \sigma_{\varphi}=\frac{\sqrt{3}}{2} \sigma_{\theta}$

and strains are:

$\dot{\varepsilon}_{\theta}=\mathbf{0}$

\footnotetext{
*orresponding author: grebe@uoradea.ro
} 
$\dot{\varepsilon}_{\varphi}=-\dot{\varepsilon}_{\mathrm{t}}$

$\dot{\bar{\varepsilon}}=\frac{2}{\sqrt{3}} \dot{\varepsilon}_{\varphi}=-\frac{2}{\sqrt{3}} \dot{\varepsilon}_{\mathrm{t}}$

Using the considerations of F. Jovane [7], also F.U Enikeev and A.A Kruglov [8], respectively, of which the thickness is uniform on all directions, one may obtain a relationship for R and average thickness, $\bar{s}$, respectively,

$\mathbf{R}=\frac{\mathbf{a}^{2}+\mathbf{h}^{2}}{2 \mathbf{h}}$

and

$\overline{\mathbf{s}}=\mathbf{s}_{0} \frac{\mathrm{a}^{2}}{\mathrm{a}^{2}+\mathrm{h}^{2}}$

where $\mathrm{h}$ is the sphere height at the instance $t$, and $a$ is the initial radius of the sample sheet (the input parameter Sample diameter).

Although, for an optimal strain rate, $\dot{\bar{\varepsilon}}_{o p t}$, experimentaly obtained, at which one may consider that the forming process occurs, i.e. the strain rate that the sensitive index $m$ has the highest value, and the process temperature known, G. Giuliano [5] had obtained the expressions for the preasure, as function of the sphere relative to height, $\mathrm{H}=\mathrm{h} / \mathrm{a}$ :

$\bar{\sigma}=\frac{p a}{4 s_{0}} \frac{\left(1+H^{2}\right)^{2}}{H}$

$\dot{\bar{\varepsilon}}=\frac{2 \mathrm{H}}{1+\mathrm{H}^{2}} \cdot \dot{\mathbf{H}}$

and

$\mathbf{p}=\frac{4 s_{0} \mathrm{~K} \dot{\bar{\varepsilon}}_{\mathrm{opt}}^{\mathrm{m}}}{\mathrm{a}} \frac{\mathrm{H}}{\left(1+\mathrm{H}^{2}\right)^{2}} ; \quad$ where $\mathbf{H}=\sqrt{\mathrm{e}^{\dot{\bar{\varepsilon}}_{\mathrm{opt}} \mathrm{t}}-1}$

\section{Results and discussion}

There were setup two input parameters, namely: P1Sample diameter and P8-Sample Thickness, and three output parameters P5-Equivalent Stress Maximum, P6Total Deformation Maximum and P7-Equivalent Plastic Strain Maximum, respectively, shows in fig. 2. For each of these parameters was monitored the only influence, the Parameter Correlation operation was done for this reason after the Design Points was calculated and updated, fig. 3. Updating the Design Points were realized the map of the Correlation Parameter System, fig. 4. This update offers a complete set of tools for study and analyzes the influence of input parameters, on output parameters, fig. 5. Examples of the Correlation Scatter between input parameters and output parameters(pairs composed by one input parameter and one output parameter) are shown in fig. 6 to fig. 8 . The fig. 9 shows the influence magnitude of one input parameter on one output parameter: the value 1 means good influence,

\begin{tabular}{|c|c|c|}
\hline \multicolumn{2}{|c|}{ Outline of Schematic B2: Parameters Correlation } & × \\
\hline & A & B \\
\hline 1 & & Enablec \\
\hline 3 & $\square$ Input Parameters & \\
\hline 4 & $\square$ Explicit Dynamics (ANSYS) (A1) & \\
\hline 5 & lp P1-Sample_diameter & 目 \\
\hline 6 & lp P8 - Sample_Thickness & 目 \\
\hline 7 & $\Xi$ Output Parameters & \\
\hline 8 & $\square$ Explicit Dynamics (ANSYS) (A1) & \\
\hline 9 & p4 P5 - Equivalent Stress Maximum & \\
\hline 10 & pe P6 - Total Deformation Maximum & \\
\hline 11 & $\begin{array}{l}\text { P7 - Equivalent Plastic Strain } \\
\text { Maximum }\end{array}$ & \\
\hline 12 & $\square$ Charts & \\
\hline 13 & $\checkmark$ 圈 Correlation Matrix & \\
\hline 14 & $\checkmark \mid$ Ill Sensitivities & \\
\hline 15 & $\checkmark \|_{1}$ Determination Histogram & \\
\hline 16 & $\checkmark$ 圈 Determination Matrix & \\
\hline 17 & $\checkmark \%$ Correlation Scatter & \\
\hline
\end{tabular}

Fig. 2. The input and output parameters settings

\begin{tabular}{|c|c|c|c|c|c|c|}
\hline \multicolumn{7}{|c|}{ Table of Design Points } \\
\hline & A & B & c & D & E & $\mathrm{F}$ \\
\hline 1 & Name $V$ & $\begin{array}{c}\text { P1- } \\
\text { Sample_dia.... }\end{array}$ & $\begin{array}{c}\text { P8- } \\
\text { Sample_Th... }\end{array}$ & $\begin{array}{c}\text { P5- } \\
\text { Equiv... } \\
\text { Stress - } \\
\text { Maxi... }\end{array}$ & $\begin{array}{l}\text { P6 - Total } \\
\text { Deform... } \\
\text { Maximum }\end{array}$ & $\begin{array}{l}\text { P7 - Equivalent } \\
\text { Plastic Strain } \\
\text { Maximum }\end{array}$ \\
\hline 2 & Units & $\mathrm{mm}$ & $\mathrm{mm}$ & $\mathrm{MPa}$ & $\mathrm{mm}$ & $m m m^{\wedge}-1$ \\
\hline 3 & Current & 20 & 1.2 & 610.14 & 15.025 & 0.29494 \\
\hline 4 & DP 1 & 20 & 0.8 & 537.52 & 15.11 & 0.30247 \\
\hline 5 & $\mathrm{DP} 2$ & 20 & 1.2 & 791.3 & 15.114 & 0.36016 \\
\hline 6 & DP 3 & 20 & 1.29 & 717.55 & 15.147 & 0.35138 \\
\hline 7 & DP 4 & 20 & 2 & 768.82 & 15.236 & 0.67749 \\
\hline 8 & DP 5 & 44.5 & 0.8 & 653.72 & 15.147 & 0.76856 \\
\hline 9 & DP 6 & 44.5 & 1.2 & 956.15 & 16.496 & 0.58829 \\
\hline 10 & DP 7 & 44.5 & 1.29 & 968.12 & 16.375 & 0.60468 \\
\hline 11 & DP 8 & 44.5 & 2 & 990.5 & 16.584 & 0.589 \\
\hline 12 & DP 9 & 51 & 0.8 & 747.27 & 15.764 & 0.75979 \\
\hline 13 & DP 10 & 51 & 1.2 & 887.47 & 15.94 & 0.56823 \\
\hline 14 & DP 11 & 51 & 1.29 & 984.58 & 16.547 & 0.55964 \\
\hline 15 & DP 12 & 51 & 2 & 983.52 & 16.076 & 0.54173 \\
\hline 16 & DP 21 & 18.648 & 1.1813 & $\frac{3}{x}$ & $\frac{3}{x}$ & $\frac{3}{x}$ \\
\hline
\end{tabular}

Fig.3. The Design Points updated table

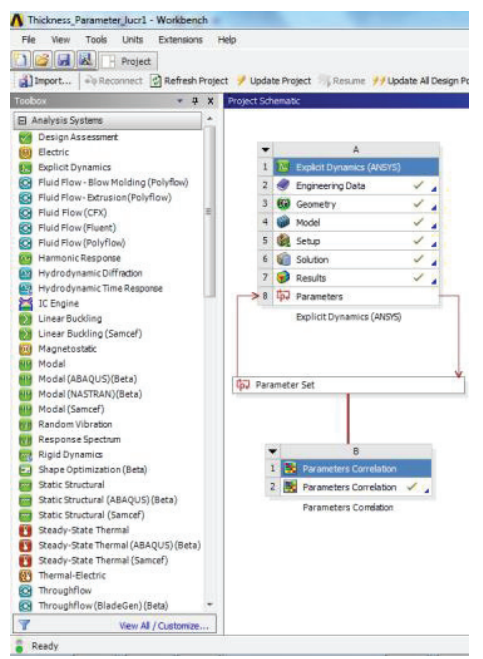

Fig. 4. Analysis system settings 


\begin{tabular}{|c|c|c|}
\hline \multicolumn{2}{|c|}{ Outline of Schematic B2: Parameters Correlation } & 7 \\
\hline & A & B \\
\hline 1 & & Enabled \\
\hline 2 & $\boxminus \checkmark$ Parameters Correlation & \\
\hline 3 & $\boxminus$ Input Parameters & \\
\hline 4 & $\square$ Explicit Dynamics (ANSYS) (A1) & \\
\hline 5 & Ґр P1-Sample_diameter & 目 \\
\hline 6 & lp P8-Sample_Thickness & 目 \\
\hline 7 & $\square$ Output Parameters & \\
\hline 8 & $\square$ Explicit Dynamics (ANSYS) (A1) & \\
\hline 9 & P4] P5 - Equivalent Stress Maximum & \\
\hline 10 & P6 - Total Deformation Maximum & \\
\hline 11 & $\begin{array}{l}\text { P7 - Equivalent Plastic Strain } \\
\text { Maximum }\end{array}$ & \\
\hline 12 & $\Xi$ Charts & \\
\hline 13 & $\checkmark$ 圈 Correlation Matrix & \\
\hline 14 & $\checkmark \mid$ all Sensitivities & \\
\hline 15 & $\checkmark \|_{1}$ Determination Histogram & \\
\hline 16 & V圈 Determination Matrix & \\
\hline 17 & $\checkmark$ Correlation Scatter & \\
\hline
\end{tabular}

Fig. 5. The Parameters Correlation updated table

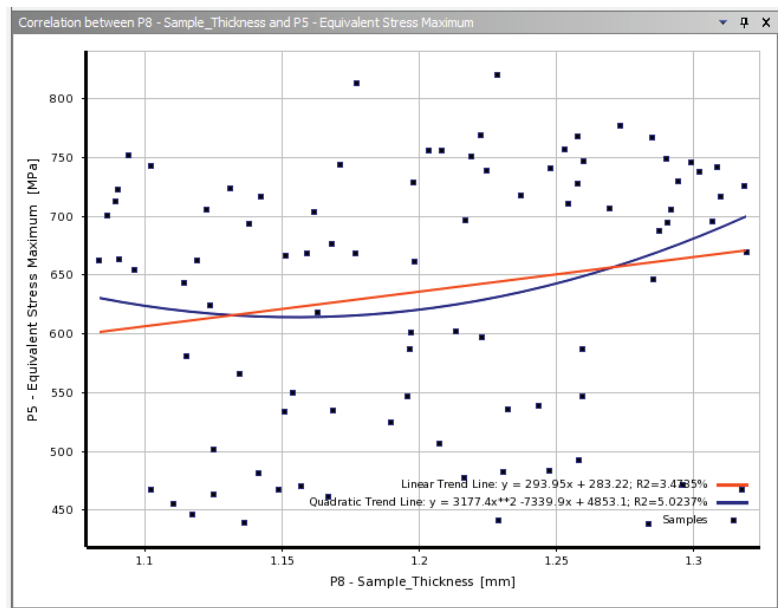

\begin{tabular}{|c|c|c|c|}
\hline \multicolumn{3}{|c|}{ Properties of Outline A17: Correlation Scatter } & \multirow{2}{*}{$\frac{7 x}{C}$} \\
\hline & A & B & \\
\hline 1 & Property & Value & Enabled \\
\hline 2 & \multicolumn{3}{|l|}{ I Chart } \\
\hline 3 & $\begin{array}{l}\text { Display } \\
\text { Parameter Full } \\
\text { Name }\end{array}$ & 目 & \\
\hline 4 & \multicolumn{3}{|l|}{ I Axes } \\
\hline 5 & $\mathrm{X}$ Axis & P8 - Sample_Thickness & \\
\hline 6 & Y Axis & P5 - Equivalent Stress Maximum & \\
\hline 7 & \multicolumn{3}{|l|}{ - Trend Lines } \\
\hline 8 & Linear & $y=293.95 x+283.22 ; R 2=3.4735 \%$ & 目 \\
\hline 9 & Quadratic & $\begin{array}{l}y=3177.4 x * * 2-7339.9 x+4853.1 \\
R 2=5.0237 \%\end{array}$ & $\nabla$ \\
\hline
\end{tabular}

Fig. 6. The Correlation Scatter, between P8 and P5 parameters

otherwise, the increasing of the input parameter, produce an increasing of one output parameter. A negative value means an inverse influence: the increasing of the input parameter, produce a decreasing of the output parameter. The Sensitivities of the output parameters with respect to the input parameters represents the major influence(positive graph), or minor influence(negative

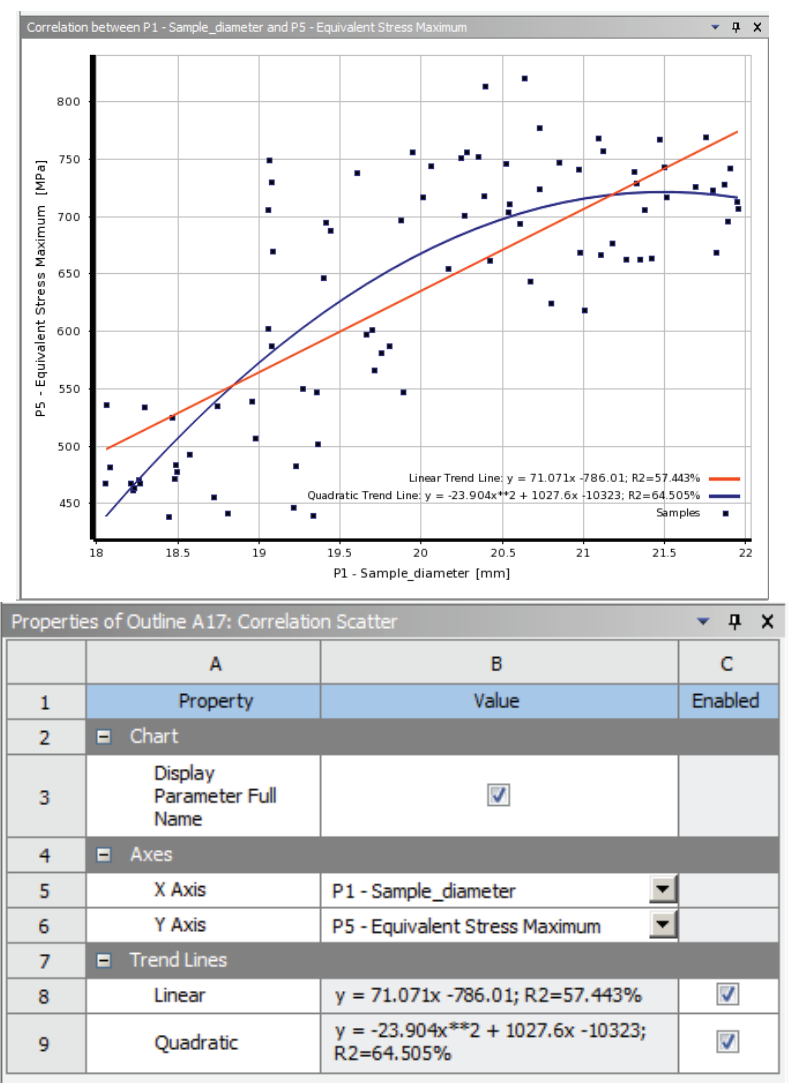

Fig. 7. Correlation Scatter between P1 and P5 parameters

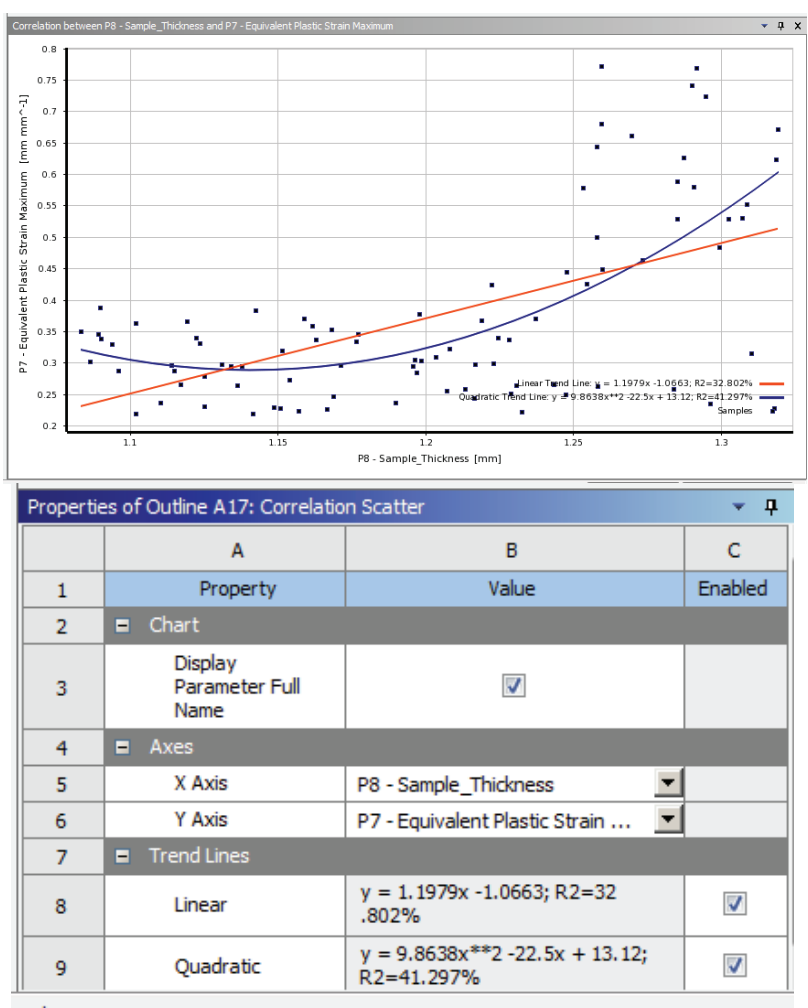

Fig. 8. Correlation Scatter between P8 and P7 parameters

graph). The fig. 11 presents the determination (the high value means the strong influence). The greatest value possible is 1 . 


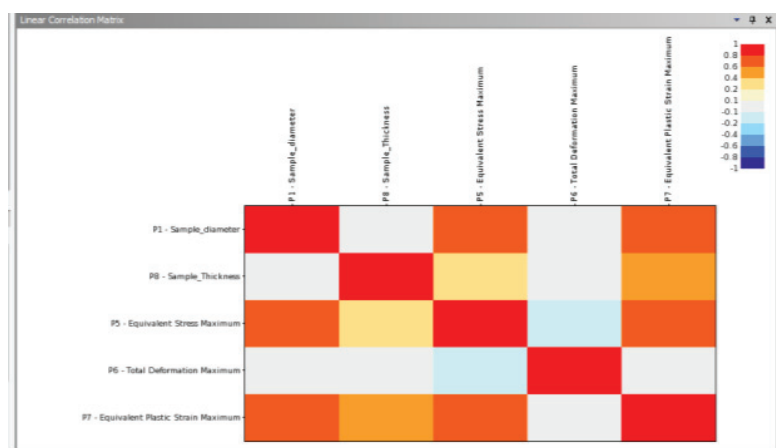

Fig. 9. The Correlation Matrix

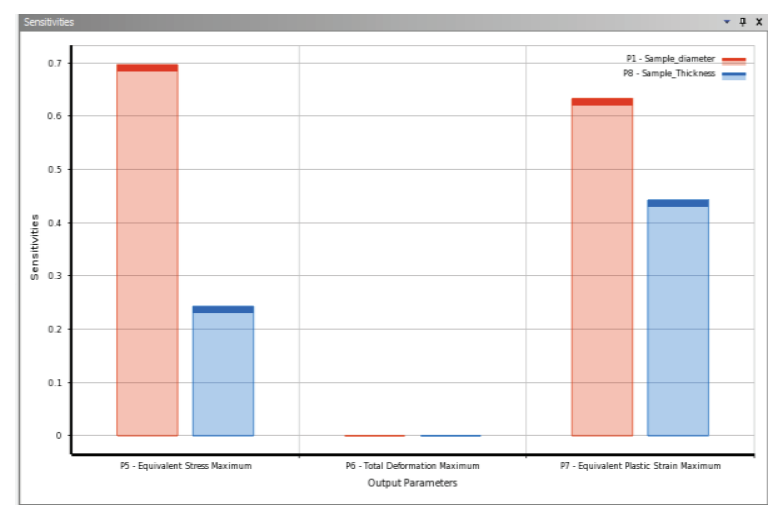

Fig. 10. The Sensitivities of output parameters on input parameters

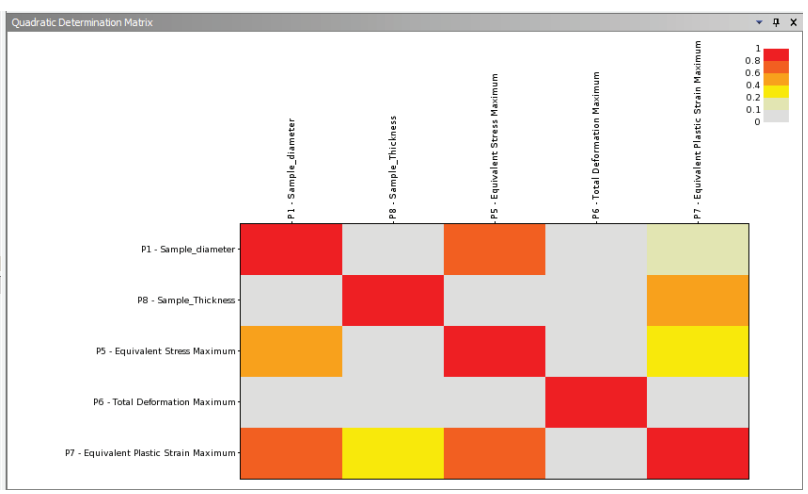

Fig. 11. Determination Matrix

The fig. 12 shows the summary of the Correlation Parameters expressed in value comprised between -1 and +1 . The table highlighted in fig. 12 presents, also, the start of Design Points table.

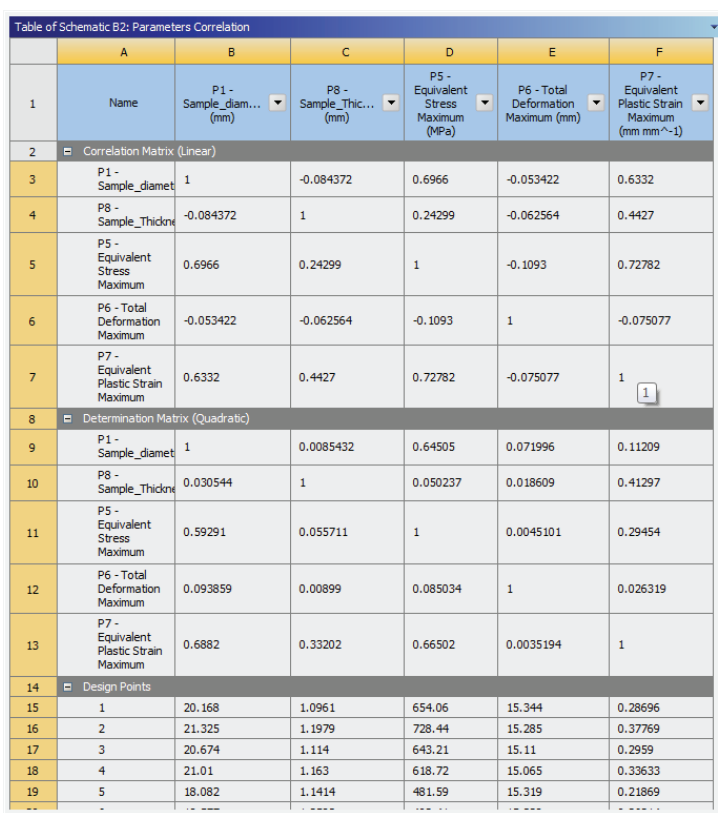

Fig. 12. Values of input and output parameters correlation

\section{References}

[1]. A.A. Bochvar, and Z.A. Sviderskaia, "Superplasticity in Zinc-Aluminum Alloys," Izv. Akad. Nauk SSSR, Otd. Tekh. Nauk, 9 (1945), 821-827.

[2]. W.A. Backofen, I.R. Turner, D.H. Avery Superplasticity in an Al-Zn Alloy, Trans. ASM, 57 (1964), pp. 980-990.

[3]. N. Chandra, Constitutive behavior of superplastic materials, International Journal of Non-Linear Mechanics 37 (2002) 461\}484

[4]. F. Dunne, N. Petrinic, Introduction to Computational Plasticity, Oxford University Press, 2005.

[5]. G. Giuliano, Superplastic forming of advanced metallic materials, Methods and Applications, Oxford, C Woodhead Publishing Limited, 2011.

[6]. G. Grebenişan and S. Mureşan, Numerical Study of Volumic Forming On Superplastic Behaviour, Annals of The University of Oradea. Fascicle of Management and Technological Engineering, Volume XVI (VI), ISSN 1583-0691, DOI: 10.15660/AUOFMTE.2007.714, 2007.

[7]. F. Jovane, An approximate analysis of the superplastic forming of a thin circular diaphragm: theory and experiments, Int. J. Mech. Sci., Pergamon Press. 1968. Vol. 10, pp. 405-427. Printed in Great Britain.

[8]. F.U. Enikeev and A.A. Kruglov, An analysis of the superplastic forming of a thin circular diaphragm International Journal of Mechanical Science, 37 ( 5 ): $473-483$ 